\title{
Analysis of Chinese Agricultural Product Trade
}

\section{Yijun Zhang}

Qinghai University, Xining 810000, Qinghai Province, China

\begin{abstract}
This paper clarifies the status of Chinese agricultural product trade through the calculation of Chinese agricultural product trade competitive advantage index for a total of 21 years from 1999 to 2019.
\end{abstract}

Keywords: Agricultural products; Trade status; Trade competitive advantage index

Publication date: April, 2021; Publication online: 30 April, 2021

*Corresponding author: Yijun Zhang, 1076762021@qq.com

\section{Preface}

China has now developed into a large agricultural trade country with a high reputation in the world. Through detailed analysis of the comparative advantages of Chinese agricultural product trade, it finds out the existing problems in Chinese agricultural product trade, and proposes strategies to promote the development of Chinese agricultural product trade

\section{Current status of Chinese agricultural trade}

Chinese agricultural product trade exhibits the following characteristics under the combined effects of national macro-control, international environment, natural climate and other factors:

Table 1. Status quo of Chinese agricultural trade

\begin{tabular}{ccccc}
\hline Year & $\begin{array}{c}\text { Total agricultural } \\
\text { imports and exports }\end{array}$ & $\begin{array}{c}\text { Total agricultural } \\
\text { exports }\end{array}$ & Total agricultural imports & $\begin{array}{c}\text { Total agricultural } \\
\text { trade balance }\end{array}$ \\
\hline 1999 & 221.3 & 138.7 & 82.6 & 56.1 \\
2000 & 268.2 & 156.2 & 112.0 & 44.2 \\
2001 & 279 & 160.7 & 118.3 & 42.4 \\
2002 & 305.9 & 181.4 & 124.5 & 56.9 \\
2003 & 403.6 & 214.3 & 189.3 & 25.0 \\
2004 & 514.2 & 233.9 & 280.3 & -46.4 \\
2005 & 558.3 & 271.8 & 286.5 & -14.7 \\
2006 & 630.2 & 310.3 & 319.9 & -9.6 \\
2007 & 775.9 & 409.7 & 366.2 & 43.5 \\
2008 & 985.5 & 583.3 & 402.2 & 181.1 \\
2009 & 921.4 & 395.9 & 525.5 & -129.6 \\
2010 & 1219.6 & 494.1 & 725.5 & -231.4 \\
2011 & 1540.4 & 601.3 & 939.1 & -337.8 \\
2012 & 1757.7 & 632.9 & 1124.8 & -491.9 \\
2013 & 1867 & 678.3 & 1188.7 & -510.4 \\
2014 & 1945 & 719.6 & 1225.4 & -505.8 \\
2015 & 1875.6 & 706.8 & 1168.8 & -462 \\
2016 & 1845.6 & 729.9 & 1115.7 & -385.8 \\
\hline
\end{tabular}




\begin{tabular}{lcccc}
\hline 2017 & 2013.9 & 755.3 & 1258.6 & -503.3 \\
2018 & 2168.1 & 797.1 & 1371 & -573.9 \\
2019 & 2300.7 & 791 & 1509.7 & -718.7 \\
\hline
\end{tabular}

Unit: USD 100 million

Note: Data source "China Statistical Yearbook"

\subsection{The overall scale of Chinese agricultural imports and exports is on the rise}

Table 1 shows that the total import and export trade of China's agricultural products has increased from 22.13 billion US dollars in 1999 to 230.07 billion US dollars in 2019 , an increase of $940 \%$, with annual growth rates of $21.2 \%, 4.0 \%, 9.6 \%, 31.9 \%, 27.4 \%$, and $8.6 \%$. $\%, 12.9 \%$, $23.1 \%, 27.0 \%,-6.5 \%, 32.4 \%, 26.3 \%, 14.1 \%, 6.2 \%, 4.2 \%$, $-3.6 \%,-1.6 \%, 9.1 \%, 7.8 \%, 6.1 \%$; of which $1999 \sim$ The growth rates of exports in 2019 were $12.6 \%, 2.9 \%, 12.9 \%$, $18.1 \%, 9.1 \%, 16.2 \%, 14.1 \%, 32.0 \%, 42.3 \%,-32.1 \%, 24.8 \%$, $21.7 \%, 5.3 \%, 7.2 \%, 6.1 \%,-1.8 \%, 3.3 \%, 3.5 \%, 5.5 \%,-0.8 \%$. With the increase in export value year by year, the growth rate of import value of agricultural products has been even more dramatic. From 1999 to 2019, they were $35.6 \%, 5.6 \%$, $5.2 \%, 52.1 \%, 48.1 \%, 2.2 \%, 11.7 \%, 14.5 \%$, and $9.8 . \%$, $30.7 \%, 38.1 \%, 29.4 \%, 19.8 \%, 5.7 \%, 3.1 \%,-4.6 \%,-4.5 \%$, $12.8 \%, 9.9 \%, 10.1 \%$, which are all higher than the total growth of trade volume and total export volume in each year Growth rate.

\subsection{Chinese agricultural trade balance is gradually decreasing}

Table 1 shows that from the perspective of trade balance, Chinese agricultural trade has gradually reduced from a surplus of $\$ 5.61$ billion in 1999 to a deficit of $\$ 71.87$ billion in 2019. In the same period, China's overall product balance was 29.23 billion U.S. dollars in surplus in 1999 and 422.74 billion U.S. dollars in surplus in 2019. The overall trend is that the trade surplus is strengthening. It can be seen that the overall advantage of Chinese agricultural products is weakening, and agricultural products have been hit by higher than industrial impacts since entering the WTO.

2.3 The share of agricultural products trade in Chinese total trade has declined

Although Chinese agricultural product trade has grown rapidly, the share of agricultural product trade in Chinese total foreign trade has shown a declining trend. The proportion of agricultural products trade in China's total trade from 1999 to 2019 was $6.1 \%, 5.7 \%, 5.4 \%, 4.9 \%, 4.7 \%$, $4.4 \%, 3.9 \%, 3.6 \%, 3.6 \%, 3.8 \%, 4.2 \%, 4.1 \%, 4.2 \%, 4.6 \%$,
$4.5 \%, 4.5 \%, 4.7 \%, 5.0 \%, 4.9 \%, 4.7 \%, 5.0 \%$, an overall decrease of 1.11 percentage points within 21 years.

3 Discrimination and analysis of the
comparative advantage of agricultural
products

\subsection{Overview of comparative advantage theory}

Comparative advantage means that if the opportunity cost of producing a product in a country (measured by other products) is lower than the opportunity cost of producing the product in other countries, then the country has a comparative advantage in producing the product. Compared with other industries, trade in agricultural products is more dependent on resource endowments and their determined comparative advantages. At the same time, the comparative advantage of agricultural products is not static or static, especially when the resource endowment structure changes, the comparative advantage will dynamically evolve over time. Dynamic comparative advantage provides the possibility to avoid falling into the trap of comparative advantage ${ }^{[1]}$. The traditional comparative advantage theory ignores technological progress and time factors, which damages the broadness and applicability of the theory to a certain extent, making it unable to make a satisfactory explanation for the changes in the contemporary international trade pattern ${ }^{[2]}$. Therefore, the calculation indicators of agricultural products in this article are all using dynamic comparative advantage indicators, which is also in line with the current trend of increasing emphasis on dynamic comparative advantages.

According to the principle of comparative advantage, the geographical division of labor should abide by the principle: no matter whether its production has absolute advantages or disadvantages compared with other regions, each region should produce products with relative advantages through foreign trade or Domestic trade, import or transfer of products with relative disadvantages can achieve the best regional and national resource allocation efficiency and the largest welfare ${ }^{[3]}$.

\subsection{Index selection}

A representative indicator of the comparative advantage of 
agricultural trade is the Trade Competitive Advantage Index (TC), which is widely used to measure intra-industry trade advantages. It is mainly determined by the ratio of the import and export trade balance of a certain agricultural product to the total trade volume in a certain period of time. The specific formula is:

$\mathrm{TC}=(\mathrm{X}-\mathrm{M}) /(\mathrm{X}+\mathrm{M})$

In the formula, $\mathrm{X}$ is the export value of a certain agricultural product in a certain period, and $\mathrm{M}$ is the import value of a certain agricultural product in a certain period. The value range of $\mathrm{TC}$ is $-1 \leq \mathrm{TC} \leq 1$. When $-1 \leq \mathrm{TC}<-0.8$, the industry has a very obvious comparative disadvantage; when $-0.8 \leq \mathrm{TC}<-0.5$, the industry has a relatively obvious comparative disadvantage;- When $0.5 \leq \mathrm{TC}<0$, the industry is in an unobvious comparative disadvantage; when $0 \leq \mathrm{TC}<0.5$, the industry is in an unobvious comparative advantage; when $0.5 \leq \mathrm{TC}<0.8$, the industry has a relatively obvious comparative advantage; $0.8 \leq$ When $\mathrm{TC}<1$, the industry has a very obvious comparative advantage.

\subsection{Scope of agricultural product research and analysis}

The article selects 9 types of agricultural products from 2 representative categories from the Standard International Trade Classification (SITC) for analysis. They are (00) live animals, (01) meat and meat preparations, (02) dairy products and birds' eggs, (03) fish, crustaceans, molluscs and aquatic invertebrates, and preparations thereof, (04) cereals and cereal preparations, (05) vegetables and fruits, (06) sugar, sugar preparations and honey, (07) coffee, tea, cocoa, spices, and manufactures thereof; SITC4 animal and vegetable oils, fats and wax.

\subsection{Analysis of discriminant results}

According to the selection of the above indicators and the determination of the scope of analysis, the competitive advantage index of Chinese agricultural products trade from 1999 to 2019 is shown in Table 2. From Table 2, the following points can be derived:

Table 2. Competitive advantage index of Chinese agricultural products trade

\begin{tabular}{|c|c|c|c|c|c|c|c|c|c|}
\hline Year & $\begin{array}{c}\text { Live } \\
\text { animals }\end{array}$ & $\begin{array}{c}\text { Meat and } \\
\text { meat } \\
\text { preparations }\end{array}$ & $\begin{array}{c}\text { Dairy } \\
\text { products } \\
\text { and } \\
\text { birds' } \\
\text { eggs }\end{array}$ & $\begin{array}{c}\text { Fish, } \\
\text { crustaceans, } \\
\text { molluscs and } \\
\text { aquatic } \\
\text { invertebrates, } \\
\text { and } \\
\text { preparations } \\
\text { thereof }\end{array}$ & $\begin{array}{c}\text { Cereals and } \\
\text { cereal } \\
\text { preparations }\end{array}$ & $\begin{array}{l}\text { Vegetables } \\
\text { and fruits }\end{array}$ & $\begin{array}{c}\text { Sugar, sugar } \\
\text { preparations } \\
\text { and honey }\end{array}$ & $\begin{array}{c}\text { Coffee, tea, } \\
\text { cocoa, spices, } \\
\text { and } \\
\text { manufactures } \\
\text { thereof }\end{array}$ & $\begin{array}{l}\text { Animal } \\
\text { and } \\
\text { vegetable } \\
\text { oils, fats } \\
\text { and wax }\end{array}$ \\
\hline 1999 & 0.711 & 0.161 & 0.000 & 0.376 & 0.447 & 0.778 & -0.130 & 0.925 & -0.812 \\
\hline 2000 & 0.762 & 0.083 & -0.074 & 0.304 & 0.513 & 0.731 & -0.011 & 0.913 & -0.776 \\
\hline 2001 & 0.816 & 0.169 & -0.066 & 0.321 & 0.348 & 0.695 & -0.414 & 0.925 & -0.736 \\
\hline 2002 & 0.733 & 0.029 & -0.167 & 0.295 & 0.539 & 0.720 & -0.105 & 0.920 & -0.872 \\
\hline 2003 & 0.472 & -0.080 & -0.225 & 0.283 & 0.680 & 0.708 & -0.047 & 0.915 & -0.916 \\
\hline 2004 & 0.201 & 0.195 & -0.313 & 0.268 & -0.268 & 0.676 & -0.143 & 0.928 & -0.927 \\
\hline 2005 & 0.502 & 0.117 & -0.267 & 0.203 & 0.141 & 0.687 & -0.038 & 0.913 & -0.842 \\
\hline 2006 & 0.680 & 0.043 & -0.304 & 0.201 & 0.234 & 0.677 & -0.144 & 0.897 & -0.819 \\
\hline 2007 & 0.672 & -0.350 & -0.240 & 0.160 & 0.501 & 0.696 & 0.076 & 0.867 & -0.917 \\
\hline 2008 & 0.660 & -0.488 & -0.169 & 0.174 & 0.130 & 0.703 & 0.230 & 0.857 & -0.896 \\
\hline 2009 & 0.519 & -0.381 & -0.509 & 0.308 & -0.043 & 0.588 & 0.234 & 0.884 & -0.918 \\
\hline 2010 & 0.256 & -0.382 & -0.663 & 0.337 & -0.283 & 0.585 & 0.011 & 0.834 & -0.920 \\
\hline 2011 & 0.205 & -0.521 & -0.684 & 0.326 & -0.363 & 0.552 & -0.246 & 0.794 & -0.910 \\
\hline 2012 & 0.077 & -0.614 & -0.718 & 0.347 & -0.672 & 0.455 & -0.336 & 0.728 & -0.917 \\
\hline 2013 & 0.146 & -0.714 & -0.812 & 0.353 & -0.678 & 0.465 & -0.239 & 0.795 & -0.894 \\
\hline 2014 & -0.175 & -0.664 & -0.834 & 0.363 & -0.742 & 0.408 & -0.074 & 0.755 & -0.868 \\
\hline 2015 & 0.043 & -0.731 & -0.690 & 0.356 & -0.837 & 0.388 & -0.142 & 0.729 & -0.844 \\
\hline
\end{tabular}




\begin{tabular}{lllllllllll}
\hline 2016 & 0.243 & -0.598 & -0.856 & 0.477 & -0.656 & 0.456 & 0.181 & 0.379 & -0.812 \\
2017 & 0.214 & -0.545 & -0.891 & 0.422 & -0.640 & 0.434 & 0.203 & 0.461 & -0.809 \\
2018 & 0.138 & -0.593 & -0.896 & 0.288 & -0.551 & 0.325 & 0.216 & 0.414 & -0.759 \\
2019 & 0.012 & -0.755 & -0.913 & 0.117 & -0.468 & 0.247 & 0.158 & 0.368 & -0.781 \\
\hline
\end{tabular}

Note: Data source "China Statistical Yearbook"

\subsubsection{The competitiveness of Chinese agricultural products is generally declining}

The average competitiveness index of Chinese agricultural products from 1999 to 2019 is $0.273,0.272,0.229,0.232$, $0.199,0.069,0.157,0.163,0.163,0.133,0.076,-0.025$, $-0.094,-0.183,-0.175,-0.203,-0.192,-0.132,-0.128$, $-0.158,-0.224$ shows that the overall comparative advantage is declining. Niu Baojun (1977) studied the comparative advantage of agricultural products trade in the past ten years and concluded that the comparative advantage of the world's agricultural products is a "U"-shaped curve trajectory that first declines and then rises. The reason is that as the process of industrialization continues to intensify, the country's economic policy has gradually shifted from focusing on supporting industry to focusing on supporting agriculture. Therefore, the comparative advantage of agricultural products first declines to a certain level and then rises. It can be seen from this that Chinese agricultural products are in a steady but declining stage.

\subsubsection{The competitiveness of Chinese agricultural products}

Products with all positive TC values and comparative advantages are (00) live animals, (03) fish, crustaceans, molluscs and aquatic invertebrates, and preparations thereof, (05) vegetables and fruits, (07) coffee, tea, cocoa, spices, and manufactures thereof. 4 major types of agricultural products. It can be seen that China has a comparative advantage in these four products, especially vegetables and fruits have a stable and strong comparative advantage. From the perspective of product advantage, (05) vegetables and fruits, (07) coffee, tea, cocoa, spices, and manufactures thereof, have strong comparative advantages, and the competitiveness of the two agricultural products is gradually strengthening. (03) fish, crustaceans, molluscs and aquatic invertebrates, and preparations thereof have insignificant comparative advantages; (04) cereals and cereal preparations of two agricultural products of cereals and products are declining. The advantages of (00) live animals have changed significantly. The obvious advantage in 2014 decreased, and the significant advantage in 2014 and 2015 decreased and increased.

The products with comparatively negative TC values are (02) dairy products and birds' eggs, which have insignificant comparative disadvantages; (06) sugar, sugar preparations and honey have insignificant comparative disadvantages and fluctuate development; SITC4 animal and vegetable oils, fats and wax have Stronger than disadvantaged.

The agricultural products with positive and negative TC values are (01) meat and meat preparations, and (04) cereals and cereal preparations. Except for the comparative advantage of (01) meat and meat preparations that turned from advantage to disadvantage in 2003, the remaining years showed insignificant comparative advantages; (04) Cereals and cereal preparations showed a strong increase in comparative advantage before 2003. But cereals were at a disadvantage in 2004.

\subsubsection{Chinese agricultural products are measured in terms of intensity}

The advantages of labor-intensive products have increased, while the advantages of land-intensive products have decreased. According to data from the United Nations COMTRADE database, agricultural products that are land-intensive include (02) dairy products and birds' eggs, (04) cereals and cereal preparations, (06) sugar,sugar preparations and honey, and SITC4 animal and vegetable oils, fats and wax. The labor-intensive products include (05) vegetables and fruits, (07) coffee, tea, cocoa, spices, and manufactures thereof.

Chinese products with obvious comparative advantages are labor-intensive products and their advantages are on the rise, while Chinese land-intensive products show comparative disadvantages and their disadvantages are increasing.

\section{Conclusion}

Through the calculation and analysis of the comparative advantage index of agricultural products trade, the following conclusions are drawn: 
3.1 Advantages of Chinese agricultural product trade.

In Chinese agricultural product trade, the advantageous trade products are mostly labor-intensive products, and the inferior products are mostly land-intensive products;

3.2 The overall competitiveness of Chinese agricultural products is weakening, and the comparative advantages of labor-intensive products are increasing, but the increase is lower than the increasing disadvantages of land-intensive products. 3.3 The overall scale of Chinese agricultural trade is expanding, but at the same time the trade balance has turned from a surplus to a deficit.

In the agricultural product trade, a large number of imported products are land-intensive products and exported are labor-intensive products.

\section{Policy recommendations}

4.1 For agricultural products that already have comparative advantages, gradually open their degrees of freedom, and let the market stimulate the enthusiasm of farmers and expand their output.

Specific measures: It can reduce the middle chain from farmers to the market, realize the two-way transparency of information from the market to the farmers, and let the market directly guide the farmers' planting behavior.

4.2 For agricultural products that do not have comparative advantages, the main point of attention is to improve the quality of agricultural products.

The government subsidies will stimulate the enthusiasm of farmers and reduce the level of disadvantages. The government can take appropriate subsidies within the scope of the "green box" and "yellow box" permitted by the WTO to stimulate farmers' production and reduce farmers' market risks. In agricultural research and selection of fine varieties, such products should emphasize the advantages of quality.

4.3 The main actors of agricultural products are farmers.

In addition to policy guidance, farmers should also cultivate their ability to participate in the market and respond to the market. Such as: encourage farmers to conduct one-stop production and marketing, improve farmers' information processing and analysis capabilities, and speed up the construction of rural industry organizations such as rural cooperative organizations, agricultural product export associations, agricultural product insurance organizations, etc.

\section{References}

[1] Fu YY. Analysis of comparative advantages of China's agricultural products trade[J]. Price Monthly, 2015(01): $43-45$.

[2] $\mathrm{Su} \mathrm{ZP.} \mathrm{Analysis} \mathrm{of} \mathrm{the} \mathrm{comparative} \mathrm{advantages} \mathrm{of}$ China and the United States in grain agricultural trade[J]. Southern Agricultural Machinery, 2018(13): $108+126$.

[3] Liu LQ, Cong PX, Shen JH. Analysis on the comparative advantages of China's agricultural products trade $[\mathrm{J}]$. Foreign Economic and Trade Practices, 2013(12): 29-32.

[4] Shi MH. Problems and countermeasures of economic management in agricultural modernization construction[J]. Southern Agricultural Machinery, 2017, 48(1): $74+84$ 